\title{
An evaluation of flexible fibreoptic sigmoidoscopy
}

\author{
K D VELLACOTT, J D HARDCASTLE
}

\begin{abstract}
Results of 350 flexible flbreoptic sigmoidoscopy examinations showed a diagnostic yield of $30 \%$ compared with $6.5 \%$ by rigid sigmoidoscopy on the same patients. The mean time for the examinations was eight minutes, a distance of over $50 \mathrm{~cm}$ being visualised in $65 \%$ of the patients. Preparation of the bowel with a single phosphate enema was adequate in $95 \%$ of the patients. As an outpatient investigation for clinicians fibreoptic sigmoidoscopy is a safe, quick, and useful addition to rigid sigmoidoscopy and should result in a decrease in the number of barium enema examinations required.
\end{abstract}

\section{Introduction}

Conventional rigid sigmoidoscopy is easy to perform as an outpatient procedure on unprepared bowel and is useful in detecting lesions in the rectum. Most carcinomas and adenomatous polyps occur on the left side of the colon. In a study of 1049 colonic adenomas, $97 \%$ of which were removed endoscopically, two-thirds of the larger adenomas of $2 \mathrm{~cm}$ diameter or more were found in the sigmoid colon. Of those containing invasive carcinoma, $5 \%$ of the total polyps, $94 \%$ were in the sigmoid or lower part of the descending colon. ${ }^{1}$ This distribution emphasises the potential value of the $60 \mathrm{~cm}$-fibreoptic sigmoidoscopes, as most of these lesions would be found with this examination. It has advantages over the conventional long colonoscope in that it may be done quickly without sedation and

Department of Surgery, Queen's Medical Centre, University Hospital, Nottingham NG7 2 UH

K D VELLACOTT, FRCS, surgical research fellow (present appointment: senior registrar, Royal Devon and Exeter Hospital (Wonford), Exeter)

J D HARDCASTLE, MCHIR, FRCS, professor of surgery using a phosphate enema as the only preparation. Resistance to the widespread use of fibreoptic sigmoidoscopy has been due to the initial high cost of the instrument and accessories compared with the rigid sigmoidoscope, the necessary bowel preparation, increased time for the procedure, difficulty of use, and questionable patient acceptance. In addition, total colonoscopy will give a more complete examination and not result in missed lesions beyond the reach of the $60 \mathrm{~cm}$-sigmoidoscope. ${ }^{23}$ We have conducted this study to evaluate flexible fibreoptic sigmoidoscopy and to assess its place in the management of symptomatic patients and in screening studies.

\section{Patients and methods}

Over a two and a half-year period 350 flexible sigmoidoscopies have been performed ( 161 men, 189 women; mean age $\pm S D 57 \pm 13$, range 18-89). Indications for the examination were "diagnostic" (280), polyp surveillance (30), colorectal cancer follow-up (27), and screening of patients without symptoms who had positive faecal occult blood tests or a strong family history of colonic cancer (13). There were no specific contraindications to the examination apart from painful anal conditions, though patients known to have total colitis were not followed up in this way.

The examinations were performed in a surgical outpatient department, and all patients were prepared with a single phosphate enema half an hour previously. The instruments used were the ACM (American-Cystoscope Makers) T-91S and the Olympus TCF $1 . S$ (Key Med), both of which are $60-65 \mathrm{~cm}$ long. No sedation was necessary, and all patients were examined in the left lateral position. Six surgeons, all of whom had had experience of upper gastrointestinal endoscopy and two of colonoscopy, performed the examinations. Details of any positive findings were recorded, along with the distance inserted, adequacy of bowel preparation, reasons for any termination, and the time the procedure took. Ten patients had more than one examination but only new additional findings were recorded. More than one polyp in a patient was recorded as one positive finding, some patients having several polyps. All the adenomatous polyps were confirmed histologically, and hyperplastic polyps were not included as serious abnormalities. These findings were compared with those 
obtained on rigid sigmoidoscopy, but the study was not a direct comparison as many patients found to have low rectal lesions on rigid sigmoidoscopy did not then have a flexible examination. Student $t$ test was used for statistical analysis.

\section{Results}

Table I shows the diagnostic yield in the various groups studied. In the diagnostic group 16 cancers were detected, a distance of $27 \cdot 4 \pm 9 \cdot 9$ $\mathrm{cm}($ mean $\pm S D$ ) from the anal verge (range $10-50 \mathrm{~cm}$ ). Only two of these cancers had been seen on rigid sigmoidoscopy (table II). A

TABLE I-Diagnostic yield with flexible sigmoidoscopy

\begin{tabular}{lccc}
\hline \multicolumn{1}{c}{ Groups } & $\begin{array}{c}\text { No of } \\
\text { cases }\end{array}$ & Positive findings & Percentage \\
\hline Diagnostic & 280 & $\begin{array}{l}\text { 16 Cancers } \\
\text { 27 Adenomatous polyps }\end{array}$ & $29 \cdot 6$ \\
& & $\begin{array}{l}\text { 12 Inflammatory } \\
\text { 26 Diverticular disease } \\
\text { 2 Solitary rectal ulcers }\end{array}$ & $36 \cdot 6$ \\
Polyp surveillance & 30 & $\begin{array}{l}\text { 1 Cancer } \\
\text { 10 Adenomatous polyps }\end{array}$ & $\begin{array}{l}18 \cdot 5 \\
\text { 5 Adenomatous polyps }\end{array}$ \\
Cancer follow-up & 27 & 3 Adenomatous polyps & 46 \\
Screening & 13 & Diverticular disease & 30 \\
\hline Total & 350 & 105 & \\
\hline
\end{tabular}

\begin{tabular}{|c|c|c|}
\hline $\begin{array}{l}\text { Cancers } \\
\text { Adenomatous polyps } \\
\text { Diverticular disease } \\
\text { Inflammatory } \\
\text { Solitary rectal ulcer }\end{array}$ & $\begin{array}{r}2 / 17 \\
10 / 45 \\
0 / 29 \\
10 / 12 \\
1 / 2\end{array}$ & $\begin{array}{l}11 \cdot 8 \% \\
22 \cdot 2 \% \\
83.3 \% \\
50 \%\end{array}$ \\
\hline & $23 / 105$ & $21.9 \%$ \\
\hline
\end{tabular}

further five cancers were found by barium enema, two on the right side of the colon and three in the sigmoid. The three in the sigmoid could not be visualised by the flexible sigmoidoscope because of the narrowed bowel lumen caused by the proximal lesion. The abnormal calibre, however, and the fact that the sigmoidoscope could not be passed the full distance indicated the need for barium enema examinations, at which time the lesions were found. One patient with a carcinoma of the ascending colon was noted to have blpod on faeces at $60 \mathrm{~cm}$. With the one cancer found in the polyp surveillance group a total of 22 cancers were found in 340 patients $(6.5 \%)$. Ten adenomatous polyps were found on rigid sigmoidoscopy, and in four of these patients flexible sigmoidoscopy found further polyps higher in the bowel. Diverticular disease was not diagnosed in any case on rigid examination, but appreciable proctitis was found in 10 out of 12 patients with inflammatory bowel disease. One of the solitary rectal ulcers had been missed on rigid sigmoidoscopy as no bowel preparation had been used (table II).

In the polyp surveillance group six of the polyps were under $0.5 \mathrm{~cm}$ in diameter, the others being removed by colonoscopic polypectomy. One patient had frank carcinoma in an adenomatous polyp. All the polyps in the cancer follow-up group were under $0.5 \mathrm{~cm}$, but those in the screening group were all over $0.5 \mathrm{~cm}$. The three patients with polyps in the screened group were all asymptomatic but had positive faecal occult bloods (one patient having three large polyps from 1-2 $\mathrm{cm}$ diameter and another having two large polyps). All patients found to have polyps for the first time were further investigated by double contrast barium enema and total colonoscopy with polypectomy. Two patients in the cancer follow-up group were examined via their extraperitoneal colostomies, and no difficulty was experienced in negotiating the course of the bowel.

As may be seen from table III in over $65 \%$ of the patients the flexible sigmoidoscope was passed more than $50 \mathrm{~cm}$, and in only $2 \%$ was it not possible to go beyond $20 \mathrm{~cm}$. Cancer or diverticular disease prevented further advancement in five patients, and inadequate bowel preparation accounted for failure to reach $20 \mathrm{~cm}$ in only three patients (table IV). The mean time for the examinations was 8.3 minutes, but in those where difficulty was encountered and it was not possible to pass the sigmoidoscope beyond $30 \mathrm{~cm}$, the examination took significantly longer (table III) $(\mathrm{p}<0.01)$. Inadequate bowel preparation occurred in only 16 patients $(4.6 \%)$ and even in these the sigmoidoscope was passed beyond $30 \mathrm{~cm}$ in 10 . Three patients had an ileorectal anastomosis, two for polyposis coli and one for colitis, and the examination was terminated just above the anastomosis. Spasm, pain, or acute angulation in the sigmoid colon accounted for termination in $22 \%$ of those examined but only in 16 was this below $30 \mathrm{~cm}$ (table IV).

TABLE III-Distance passed and time taken for flexible sigmoidoscopy

\begin{tabular}{ccc}
\hline $\begin{array}{c}\text { Distance } \\
(\mathrm{cm})\end{array}$ & $\begin{array}{c}\text { No }(\%) \text { of } \\
\text { cases }\end{array}$ & $\begin{array}{c}\text { Time taken } \\
(\mathrm{min}) \pm \mathrm{SD}\end{array}$ \\
\hline$>60$ & $169(48 \cdot 3)$ & $7 \pm 2 \cdot 8$ \\
$51-60$ & $61(17 \cdot 4)$ & $9 \pm 4$ \\
$31-50$ & $82(23 \cdot 4)$ & $9 \cdot 4 \pm 4$ \\
$21-30$ & $31(8 \cdot 9)$ & $10 \pm 4 \cdot 3$ \\
$<20$ & $7(2)$ & $12 \cdot 8 \pm 5 \cdot 7$ \\
\hline & 350 & $8 \cdot 3 \pm 3 \cdot 7$ \\
\hline
\end{tabular}

TABLE IV-Reasons for termination of examination at less than full distance

\begin{tabular}{lcccc}
\hline & $<20 \mathrm{~cm}$ & $20-30 \mathrm{~cm}$ & $30-50 \mathrm{~cm}$ & Percentage \\
\hline Inadequate bowel preparation & 3 & 3 & 10 & $4 \cdot 6$ \\
Constriction due to: & 2 & 6 & 6 & $4 \cdot 0$ \\
Diverticular disease & 3 & 3 & 5 & $3 \cdot 1$ \\
Cancer & & 3 & 61 & $22 \cdot 0$ \\
Ileorectal anastamosis & 16 & 61 & 82 & $34 \cdot 6$ \\
\hline Spasm, pain, or tortuous sigmoid & 8 & 31 & & \\
\hline
\end{tabular}

No complications occurred during or after any of the examinations, and $95 \%$ of the patients were prepared to have the examination again if it was considered necessary. Of 50 patients who were questioned as to their preference of instrument, however, only $16 \%$ actually preferred the flexible to the rigid sigmoidoscope.

\section{Discussion}

Flexible fibreoptic sigmoidoscopes have been available in Britain since the latter part of 1977, since when about 200 instruments have been sold, the majority $(69 \%)$ being used by surgeons. Most reports on its use have come from the United States, where it is largely used as an office procedure.$^{3-8}$ This differs considerably from British practice, where it is mainly used for diagnosis in surgical outpatient departments. We have therefore attempted to analyse the advantages and disadvantages of the fibreoptic sigmoidoscope and suggest guidelines for its use.

\section{DIAGNOSTIC YIELD}

In a large study of 1012 cases the yield with the flexible sigmoidoscope was $3 \cdot 2$ times more than with the rigid sigmoidoscope. ${ }^{3}$ With a simple bowel preparation we found a yield of $30 \%$ in investigating patients with altered bowel habit, pain, or bleeding per rectum. In a few patients a full examination to 60 $\mathrm{cm}$ showing an entirely normal bowel is likely to reduce the number requiring a barium enema. In addition, prompt diagnosis of a malignant lesion may save several weeks of waiting for a barium enema and allow surgery to be undertaken sooner. If no lesions were found patients could be reassured immediately.

Those patients with severe diverticular disease (particularly if there was a history of recent admission) or with diverticulitis or paracolic abscess were the most difficult to examine. The instrument could often not be passed into the sigmoid, probably 
because its fixation by inflammatory reaction makes it immobile and difficult to negotiate. Though these examinations are generally unrewarding, it is still worth attempting to try to exclude a malignancy, but we would suggest that a barium enema should be performed first. Any patient who is found to have a polyp must have the remainder of the bowel examined either by a double contrast barium enema or total colonoscopy or both. Electrosurgical polypectomy can be performed through a properly insulated flexible sigmoidoscope, though we did not do so. To position the instrument for polypectomy is often painful for the patient, and we recommend sedation for this. In addition, a single phosphate enema may be inadequate for the evacuation of potentially explosive gases, ${ }^{6}$ and there is also the risk of bleeding after removal of large polyps. For patients with inflammatory bowel disease, the flexible sigmoidoscope was used only to assess whether colitis extended beyond the rectum. Those with simple proctitis and normal proximal colon were not further investigated, unless symptoms persisted. The sigmoidoscope is not recommended for use in monitoring patients with long-standing total colitis, who should be followed up by colonoscopy and multiple mucosal biopsies. A negative examination result in patients with symptoms and signs of distal large bowel obstruction may be of considerable help to the clinician, particularly if he suspects a pseudo-obstruction. The flexible sigmoidoscope can also be used to reduce sigmoid volvulus under direct vision, ${ }^{9}$ although the rigid instrument may often be satisfactory.

\section{POLYP SURVEILLANCE}

There is increasing evidence that cancers develop from adenomatous polyps, ${ }^{10}$ but the problem of how often and for how long to follow up patients after polypectomy remains unresolved. At present we are examining patients yearly after the initial total diagnostic colonoscopy. Those with one polyp in the sigmoid can probably be adequately followed up by flexible sigmoidoscopy but those with multiple polyps should probably be followed up by a combination of sigmoidoscopy and colonoscopy. In a study of 500 patients under surveillance at St Mark's Hospital, London, $90 \%$ of the polyps found beyond the reach of the flexible sigmoidoscope were less than $7 \mathrm{~mm}$ diameter and colonoscopy took more than twice the time to perform. ${ }^{11}$ In another group of 197 patients one malignant polyp and 186 further polyps were found, though it was not clear how often these patients had been followed up previously. ${ }^{3}$ It has been suggested that where only a single polyp was present follow-up may be stopped after four years if no new lesion has been found. ${ }^{12}$ It is hoped that the results of large studies of polyp surveillance will help to clarify how best to follow up these patients.

\section{CANCER FOLLOW-UP}

The follow-up of patients with postresection cancer in a general surgical outpatient department is generally unrewarding. In a study of 180 patients with colonic cancer 71 developed recurrence but $58 \%$ of these presented at times other than their routine appointment. Of the remaining $42 \%$, most had symptoms and only $15 \%$ were resectable with a $2 \%$ five-year survival rate. ${ }^{13}$ The flexible sigmoidoscope gives the opportunity of detecting suture line recurrences and metachronous tumours at an early stage. Those patients who have had a cancer resected and are found to have adenomatous polyps in the resected specimen should be followed up particularly carefully as they have an increased risk of developing a second primary tumour. ${ }^{10}$

When 132 patients with colorectal cancer were followed up by flexible sigmoidoscopy, five cancers and 12 polyps were found, three of the cancers occurring in polyps. ${ }^{3}$ We have reviewed only 27 patients so far, and the yield was not significant. The examination, however, is very easy in patients who have had part or all of the sigmoid colon removed, and the sigmoidoscope can often be passed quickly to the transverse colon. It is also possible to examine patients down a colostomy after a suitable preparation. Patients are delighted to be told that their bowel is clear of disease, and the value of patient reassurance should also be taken into account.

\section{SCREENING STUDIES}

As the examination has a much higher yield than rigid sigmoidoscopy we recommend it as a first investigation for patients at high risk of colorectal cancer and in asymptomatic patients found to have positive faecal occult bloods.

Studies in the United States have included screening of asymptomatic individuals over the age of 40 with flexible sigmoidoscopy. In 198 men and two women 53 polyps were found in 39,22 of the polyps being over $0.5 \mathrm{~cm}$ in diameter. It was concluded that this method of screening was worth while. ${ }^{14}$ In a larger study of 1000 asymptomatic individuals, however, no cancers and only 56 polyps, some of which were hyperplastic, were detected. ${ }^{15}$ It seems, therefore, that any screening with flexible sigmoidoscopy should be confined to the high-risk groups.

\section{INSTRUMENTS}

Flexible sigmoidoscopes currently available in Britain are Olympus (KeyMed) ACM (American Cystoscope Makers), Fujinon (Pyser), Machida (Eschmann), Pentax (Downs Instruments), and American Optical (Henleys). Most of the distributors supply adaptors so that their instruments may be used either from their own light sources or the Olympus light source. The costs range from $£ 1500-4500$ inclusive of light source compared with over $£ 6000$ for a colonoscope. After about 2000 examinations a long colonoscope requires replacement of its fibres, but a sigmoidoscope can probably perform at least three times as many examinations before needing replacement. By doing more examinations by the flexible sigmoidoscope, the colonoscope can be made to last longer with resultant saving of costs. If polyp surveillance is being undertaken, however, access to colonoscopy facilities must be available. To obtain maximum benefit from a flexible sigmoidoscope, it should be looked after by designated nurses or assistants who clean the instrument scrupulously to prevent cross-infection and are experienced in how to set up, maintain, and store the equipment. In our 350 examinations with two instruments we have had no serious problems, and the instruments have not had to be returned for repair.

\section{OPERATORS AND TECHNIQUES}

To get the maximum benefit from flexible sigmoidoscopy it should not be learnt on a trial-and-error basis. Surgeons or gastroenterologists with experience of gastroscopy will learn the initial technique fairly quickly but those who have not should learn the technique from an experienced operator to prevent complications, damage to the instruments, and to obtain the maximum diagnostic benefit. Complicated manoeuvres should be reserved for the experienced colonoscopist, and techniques necessary to obtain maximum visualisation of the bowel will be acquired with practice. ${ }^{16}$

We are now undertaking a trial comparing double contrast barium enema and flexible sigmoidoscopy. Preliminary results of this study show flexible sigmoidoscopy to be more accurate at detecting polyps in the sigmoid colon than barium enemas. In 
those patients investigated for rectal bleeding and left-sided abdominal pain who had a normal sigmoidoscopic examination to $60 \mathrm{~cm}$ no lesions were detected by barium enema in the remainder of the bowel. This suggests that a flexible sigmoidoscopic examination alone may be adequate, and possibly therefore some patients could be spared a barium enema. When an equivocal result in the sigmoid region is obtained on radiography the flexible sigmoidoscope can usually clarify the diagnosis, but this is unnecessary if the sigmoidoscopy is the first investigation.

We believe that the investment in a flexible sigmoidoscope may be justified for three reasons:

(1) An accurate diagnosis will be obtained more quickly.

(2) It will lead to a decrease in the number of barium enemas required and a higher diagnostic accuracy.

(3) With a combination of colonoscopy and flexible sigmoidoscopy in the follow-up of polyp patients and a reduction in the numbers needing to be investigated because of equivocal barium enemas, fewer colonoscopies will need to be performed. This will result in a longer life span for the colonoscopes. Though some patients will be spared colonoscopy, flexible sigmoidoscopy should in the main be considered as an extension of rigid sigmoidoscopy rather than as an alternative to colonoscopy. Owing to the simpler method of bowel preparation and no sedation, greater numbers may be examined as outpatients than will ever be possible by colonoscopy.

We believe that the early results with these instruments justify their more extensive use and that they will result in considerable benefit to both patients and clinicians.

We thank Mr T W Balfour for his considerable advice and Mrs C Mangham for typing the paper.

Requests for reprints should be addresssd to Mr K D Vellacott, Royal Devon and Exeter Hospital (Wonford), Exeter.

\section{References}

${ }^{1}$ Gillespie PE, Chambers TJ, Chan KW, Doronzo F, Morson BC, Williams CB. Colonic adenomas-a colonoscopy survey. Gut 1979;20:240-5.

2 Ibister WH. Flexible fibreoptic sigmoidoscopy-an alternative to colonoscopy? NZ Med f 1980;92:283-5.

: Marks G, Boggs WH, Castro AF, Gathright JB, Ray JE, Savati E. Sigmoidoscopic examination with rigid and flexible fibreoptic sigmoidoscopies in the surgeons office: A comparative prospective study of effectiveness in 1012 cases. Dis Colon Rectum 1979;22:162-8.

${ }^{4}$ Holt RW, Wherry DC. Why flexible fiberoptic sigmoidoscopy is important in the geriatric patient. Geriatrics $1979 ; 34: 85-8$.

${ }^{5}$ Bohlman TW, Katon RM, Lipshutz GR, McCool MF, Smith FW, Melnyk CS. Fiberoptic pansigmoidoscopy: An evaluation and comparison with rigid sigmoidoscopy. Gastroenterology $1977 ; 72: 644-9$.

${ }^{5}$ Christie JP. Flexible sigmoidoscopy-why, where and when ? Am $\mathcal{f}$ Gastroenterol $1980 ; 73: 70-2$.

7 Manier JW. Fiberoptic pansigmoidoscopy: An evaluation of its use in an office practice. Gastrointest Endosc 1978;24:119-20.

${ }^{8}$ Winnan G, Berci G, Panish J, Talbot TM, Overholt BF, McCallum RW. Superiority of the flexible to the rigid sigmoidoscope in routine proctosigmoidoscopy. N Engl f Med 1980;302:1011-2.

${ }^{9} \mathrm{O}$ 'Connor JJ. Reduction of sigmoid volvulus by flexible sigmoidoscopy. Arch Surg 1979;114:1092.

1" Morson BC. The polyp-cancer sequence in the large bowel. Proc $R$ Soc Med $1974 ; 67: 451-7$.

${ }^{11}$ Henry LG, Condon RE, Schulte WJ, Aprahaman C, Decosse JJ. Risk of recurrence of colon polyps. Ann Surg 1975;182:511-5.

12. Cochrane JPS, Williams JT, Faber RG, Slack WW. Value of outpatient follow-up after curative surgery for carcinoma of the large bowel. $\mathrm{Br}$ Med F 1980;280:593-5.

${ }^{13}$ Lipshutz GR, Katon RM, McCool MF, et al. Flexible sigmoidoscopy as a screening procedure for neoplasia of the colon. Surg Gynecol Obstet 1979;148:19-22.

1 Goldsmith O, Frankl H, Gerety D, Masse C, Colbert P, Sanders P. Fiberoptic sigmoidoscopy in an asymptomatic population. Gastrointest Endosc $1977 ; \mathbf{2 3}: 228$.

${ }^{15}$ Coller JA. Technique of flexible fiberoptic sigmoidoscopy. Surg Clin North Am 1980;60:465-79.

(Accepted 12 August 1981)

\section{MATERIA NON MEDICA}

\section{Effigies and the like}

When travelling in the country my wife and I often take the opportunity of visiting churches, sometimes a small ancient church in a village, sometimes one of our great cathedrals. There is usually much of interest including effigies or statues of past worthies: Crusader knights with their legs crossed, local lords and ladies, and, of course, church dignitaries, sometimes recumbent, as on their death beds, sometimes standing. Of these last probably the most unusual is that of John Donne in St Paul's Cathedral, carved from life, standing in his shroud as for burial.

Recently, on a visit to Orkney, we visited the fine Cathedral of St Magnus, founded in the twelfth century by the Norsemen. Here we saw a tomb with a life-size recumbent effigy described as that of John Rae, MD, FRGS, FRCS, the Arctic explorer who discovered the fate of Sir John Franklin.

Rae, an Orcadian, was a remarkable man. He qualified in Edinburgh in 1833 and then joined the Hudson's Bay Company, first as ship's surgeon and then as resident surgeon at Moose Fort. He made various scientific studies and devised a hot air balloon fuelled by solar heat. But arctic exploration was his great interest and he learnt much from the Eskimos. On one occasion he and his party hauled their boat 70 miles from Great Bear Lake to the Mackenzie River. On another he walked 40 miles in snow shoes in seven hours.

In 1847 he first went to London to join an expedition to try to discover the fate of Sir John Franklin, who had sailed away in 1845 with the naval vessels Erebus and Terror to try to find the north-west passage to the Pacific. Nothing was found. In 1854, however, Rae went on a further exploration which did find various relics and other evidence, though no bodies.

Rae's last years were spent in London, where he took a keen interest in colonial affairs. His statue shows him lying in a most unusual position, half on his side with his hands folded behind his head. $\mathrm{He}$ is in arctic clothing with his legs encased in full-length gaiters fastened with about a dozen buttons all carefully carved. I thought at first that this must have been how he was found-frozen to death in distant snows like Captain Scott. Not so: he died in London in 1893 of influenza and "congestion of the lungs." Edinburgh and its Royal College of Surgeons must be proud of him.-ROBERT C TAYLOR, retired general practitioner, Lickey, nr Birmingham.

\section{Faces at the Lonach Gathering}

The Lonach Gathering (lonach-a marsh or field) held on a meadow at Bellabeg in Strathdon is a cosy affair attended almost exclusively by locals and thus of restricted interest to the world at large by comparison with the grand royal event which takes place in a glen to the south. There is a unique feature-the march of clansmen, by which is meant the longstanding families of the glen such as Forbes, Wallace, Gordon, Stuart, Grant, Gauld, Thomson, Davidson, Anderson. I am not sure how longstanding one has to be to qualify but many men have forebears who marched at the instigation of the gathering 140 years ago. The matter is taken seriously and as I watched more than two hundred stern faces pass I was struck by how distinctive is the north-east visage. There are two male faces in the glendistinguished mainly by their noses. Heavily built, often very broadshouldered dark men with chisel faces, the tip of nose being below the junction with the columella, making them look in profile like miniature Easter Island statues; and more lightly built men, often redheaded, whose noses are snubs but not pug-like. Of course, these are stereutypes and mixtures occur such as four brothers of light complexion but with the characteristic long nose. That the glen should have these two types is testimony to the fact that the north-east of Scotland is still genetically quite isolated. I like to think the long noses - so unlike other Scottish people-are descendants of those who built the chambered cairns at Clova and who are thought to have crossed the North Sea about $2000 \mathrm{BC}$, but in the absence of any evidence of their physiognomy this is perhaps just a romantic notion.-H A F DUDLEY, professor of surgery, London. 